\title{
Controversies in cancer stem cells
}

\author{
Richard J. Jones
}

Received: 8 October 2009 / Accepted: 8 October 2009 /Published online: 23 October 2009

(C) Springer-Verlag 2009

The cancer stem cell (CSC) concept hypothesizes that a malignancy maintains a similar hierarchical structure to the normal tissue of origin, i.e., the bulk of the tumor represents differentiated progeny of rarer so-called CSCs with selfrenewal capacity [1-3]. However, while possessing the stem cell properties of self-renewal and differentiation, not all putative CSCs exhibit the multilineage potential that distinguishes "true" stem cells $[2,4]$. Thus, some investigators have preferred the term cancer-initiating cells over CSCs. Myeloid leukemias are universally regarded as providing the strongest evidence in support of the CSC concept. Fialkow and his colleagues first suggested that chronic myeloid leukemia (CML) arose from rare transformed hematopoietic stem cells (HSC) nearly 40 years ago, when they showed that both granulocytes and red blood cells from CML patients were derived from a common cell [5]. The stem cell origin of CML was confirmed more than 15 years ago when several groups utilized phenotypic characteristics of HSC to identify and isolate CML cells capable of expansion ex vivo [6]. Dick and colleagues extended these observations, showing that only the rare phenotypic primitive HSC purified from patients with both acute myeloid leukemia $[7,8]$ and CML [9] would generate leukemia in vivo when injected into nonobese diabetic/severe combined immunodeficient (NOD/SCID) mice. Tumorigenic growth in such immunodeficient mouse models remains the current gold standard for identification of CSCs.

\section{R. J. Jones $(\bowtie)$}

Sidney Kimmel Comprehensive Cancer Center at Johns Hopkins, Room 244, Bunting-Blaustein Cancer Research Building, 1650 Orleans St.,

Baltimore, MD 21231, USA

e-mail: rjjones@jhmi.edu
The CSC concept would explain not only the low clonogenic capacity of most malignancies, but also why complete treatment responses translate into cures in only a minority of cancer patients. Initial responses in cancer represent therapeutic effectiveness against the bulk cancer cells, while rarer resistant CSCs could be responsible for relapse. Putative CSCs have in fact been reported to be relatively resistant to standard anticancer therapies $[4,10$, 11], at least in part by co-opting normal stem cells' intrinsic defense mechanisms such as quiescence, efflux pumps, and detoxifying enzymes [4]. The CSC concept proposes that these cells must be eliminated to realize cures and that many active treatments may have little activity against biologically distinct CSCs [3]. Accordingly, improving the results of cancer therapy would require identification and better understanding of the biology of CSC. However, the results of biologic studies, such as gene arrays, on whole tumors are unlikely to reflect the rare CSC populations.

Although cells meeting the definition for CSCs [2] have now been described in most malignancies, with the possible exception of myeloid leukemias, there remains healthy skepticism about their true biologic significance. In fact, many investigators have proposed that CSCs may be laboratory curiosities primarily reflecting a limited robustness of NOD/SCID mice for assessing tumorigenic potential $[12,13]$. This is highlighted by a recent study comparing the growth of melanoma cells from patients in NOD/SCID and the more immunocompromised NOD/ SCID interleukin-2 receptor gamma chain null (NOG) mice. Although only about one in 100,000 unselected melanoma cells produced tumors in NOD/SCID mice, as few as one in four melanoma cells were tumorigenic when transplanted into NOG mice [13]. However, tumorigenic potential in immunocompromised mice does not necessarily imply a role in clinical tumor growth and progression. Even if 
every cell in a cancer possessed tumorigenic potential, the presence of a discreet subset responsible for treatment resistance - perhaps as a result of stem cell characteristicswould have critical clinical significance.

This special issue of the Journal of Molecular Medicine focuses on many of these unresolved issues surrounding CSCs. The term tumor/cancer stem cell was first coined nearly 40 years ago to highlight the observation that only a minority of multiple myeloma cells were capable of clonogenic growth [14, 15]. However, until recently, most investigators considered malignant plasma cells to be the tumorigenic cells in myeloma. Several groups have now suggested that myeloma CSCs are malignant memory B cells, with myeloma plasma cells representing differentiated progeny [4]. Nevertheless, controversy surrounding the exact phenotype and biology of the myeloma cells responsible for clonogenic growth remains. In their article "Cancer Stem Cells: Controversies in Multiple Myeloma," Sarah Brennan and William Matsui discuss the evidence supporting CSCs in myeloma, as well as potential explanations for the disparate findings [16].

After leukemias, brain cancers may represent the malignancy with the most evidence in support of the CSC concept. Nevertheless, the significance of brain CSCs, if any, remains unclear. Angelo Vescovi and his colleagues analyze the current state of the science on brain CSCs and especially their usefulness as emerging therapeutic targets in "Brain Cancer Stem Cells." [17]. In "Colon Cancer Stem Cells," Ruggero De Maria and his colleagues review advances in understanding normal intestinal epithelial stem cells and crypt biology, and more recent data from several groups suggesting that colon cancer may arise from transformed intestinal epithelial stem cells [18]. They further discuss the potential relevance of colon CSC and their potential as therapeutic targets.

Perhaps the major reason why many investigators question the biologic and clinical relevance of CSCs has been the absence of any definitive data showing that CSCs from any malignancy, including leukmeias, are in fact responsible for disease progression. In "Cancer Stem Cells-Clinical Relevance," I discuss emerging evidence demonstrating for the first time a clinical significance for the CSC concept [19]. As with other reviews in this issue, potential approaches for clinically targeting CSCs are also discussed. Although an old concept, only recently have CSCs really emerged as an area of active research. The ongoing rapid progress in the field ensures that it will remain an active area of translational research.

\section{References}

1. Reya T, Morrison SJ, Clarke MF, Weissman IL (2001) Stem cells, cancer, and cancer stem cells. Nature 414:105-111

2. Clarke MF, Dick JE, Dirks PB, Eaves CJ, Jamieson CH, Jones DL, Visvader J, Weissman IL, Wahl GM (2006) Cancer stem cells - perspectives on current status and future directions: AACR workshop on cancer stem cells. Cancer Res 66:9339-9344

3. Jones RJ, Matsui WH, Smith BD (2004) Cancer stem cells: are we missing the target? J Natl Cancer Inst 96:583-585

4. Matsui W, Wang Q, Barber JP, Brennan S, Smith BD, Borrello I, McNiece I, Lin L, Ambinder RF, Peacock C et al (2008) Clonogenic multiple myeloma progenitors, stem cell properties, and drug resistance. Cancer Res 68:190-197

5. Fialkow PJ, Gartler SM, Yoshida A (1967) Clonal origin of chronic myelocytic leukemia in man. Proc Natl Acad Sci U S A 58:1468-1471

6. Bedi A, Zehnbauer BA, Collector MI, Barber JP, Zicha MS, Sharkis SJ, Jones RJ (1993) BCR-ABL gene rearrangement and expression of primitive hematopoietic progenitors in chronic myeloid leukemia. Blood 81:2898-2902

7. Lapidot T, Sirard C, Vormoor J, Murdoch B, Hoang TC-CJ, Minden M, Paterson B, Caligiuri MA, Dick JE (1994) A cell initiating human acute myeloid leukaemia after transplantation into SCID mice. Nature 367:645-648

8. Bonnet D, Dick JE (1997) Human acute myeloid leukemia is organized as a hierarchy that originates from a primitive hematopoietic cell. Nat Med 3:730-737

9. Sirard C, Lapidot T, Vormoor J, Cashman JD, Doedens M, Murdoch B, Jamal N, Messner H, Addey L, Minden M et al (1996) Normal and leukemic SCID-repopulating cells (SRC) coexist in the bone marrow and peripheral blood from CML patients in chronic phase, whereas leukemic SRC are detected in blast crisis. Blood 87:1539-1548

10. Bao S, Wu Q, McLendon RE, Hao Y, Shi Q, Hjelmeland AB, Dewhirst MW, Bigner DD, Rich JN (2006) Glioma stem cells promote radioresistance by preferential activation of the DNA damage response. Nature 444:756-760

11. Li X, Lewis MT, Huang J, Gutierrez C, Osborne CK, Wu MF, Hilsenbeck SG, Pavlick A, Zhang X, Chamness GC et al (2008) Intrinsic resistance of tumorigenic breast cancer cells to chemotherapy. J Natl Cancer Inst 100:672-679

12. Kelly PN, Dakic A, Adams JM, Nutt SL, Strasser A (2007) Tumor growth need not be driven by rare cancer stem cells. Science 317:337

13. Quintana E, Shackleton M, Sabel MS, Fullen DR, Johnson TM, Morrison SJ (2008) Efficient tumour formation by single human melanoma cells. Nature 456:593-598

14. Park CH, Bergsagel DE, McCulloch EA (1971) Mouse myeloma tumor stem cells: a primary cell culture assay. J Natl Cancer Inst 46:411-422

15. Hamburger AW, Salmon SE (1977) Primary bioassay of human myeloma stem cells. J Clin Invest 60:846-854

16. Brennan SK, Matsui W (2009) Cancer stem cells: controversies in multiple myeloma. J Mol Med 87(11). doi:10.1007/s00109-0090531-7

17. Piccirillo SGM, Binda E, Fiocco R, Vescovi AL, Shan K (2009) Brain cancer stem cells. J Mol Med 87(11). doi:10.1007/s00109009-0535-3

18. Ricci-Vitiani L, Fabrizi E, Palio E, De Maria R (2009) Colon cancer stem cells. J Mol Med 87(11). doi:10.1007/s00109-0090518-4 this issue

19. Jones RJ (2009) Cancer stem cells — clinical relevance. J Mol Med 87(11). doi:10.1007/s00109-009-0552-2 this issue 